\title{
Pedicel Transpiration in Sweet Cherry Fruit: Mechanisms, Pathways, and Factors
}

\author{
Thomas O. Athoo, Andreas Winkler, and Moritz Knoche ${ }^{1}$ \\ Institute for Horticultural Production Systems, Leibniz-University Hannover, Herrenhäuser Straße 2, \\ 30419 Hannover, Germany
}

\begin{abstract}
Additional index words. Prunus avium, cuticle, peduncle, stalk, stomata, xylem
Abstract. Pedicel appearance is a good indicator of freshness in sweet cherries (Prunus avium L.). Fruit with shriveled, discolored pedicels have reduced market value. Shriveled pedicels are thought to result from postharvest water loss due to transpiration. The objectives of our study were to 1) quantify the transpiration permeances of fruit and pedicel surfaces; 2) determine the role of the fruit in pedicel transpiration; and 3) identify the effects of selected factors on pedicel transpiration. Fruit with and without pedicels were incubated under controlled conditions [usually $22{ }^{\circ} \mathrm{C}, 75 \%$ relative humidity (RH)] and their mass losses determined gravimetrically. Pedicel transpiration was calculated by subtracting measured transpiration of fruit without pedicels from that of fruit with pedicels. Cumulative pedicel transpiration increased with time. Rates of pedicel transpiration were essentially constant over the first 0 to 1.5 hours but declined thereafter, approaching an asymptote over the subsequent period of 1.5 to 96 hours over which measurements were made. Cumulative pedicel transpiration exceeded the amount of water in the pedicel, indicating that at least some of the transpired water originated from the fruit. There was no significant effect of steam girdling on pedicel transpiration suggesting that water moved from the fruit to the pedicel through the xylem (steaming prevents phloem conduction). Abrading the cuticular membrane (CM) from a pedicel surface or extracting the cuticular wax by dipping pedicels once or five times in chloroform/methanol (1:1 v/v) increased rates of transpiration 12-, 3-, and 5-fold, respectively. The water vapor permeance of the pedicel surface determined under steady-state conditions $\left(8.7 \pm 0.4 \times 10^{-4} \mathrm{~m} \cdot \mathrm{s}^{-1}\right)$ exceeded that of the fruit $(2.1 \pm 0.1 \times$ $\left.10^{-4} \mathrm{~m} \cdot \mathrm{s}^{-1}\right)$, possibly because of a more permeable $\mathrm{CM}$ and/or a higher stomatal density $\left(38.5 \pm 1.3 \mathrm{stomata} / \mathrm{mm}^{2}\right.$ for pedicels vs. $1.1 \pm 0.0$ stomata $/ \mathrm{mm}^{2}$ for fruit). Treatments known to affect stomatal opening (incubation in buffered abscisic acid at $0.1 \mathrm{~mm}$ or in $\mathrm{CO}_{2}$ - or $\mathrm{N}_{2}$-atmospheres) had no effects on pedicel transpiration. Rates of transpiration were negatively correlated with $\mathrm{RH}$ but positively with temperature. There was no effect of $\mathrm{RH}$ and/or temperature on the permeances of pedicel or fruit surfaces. From our results it is inferred that 1) pedicel transpiration is a physical process governed by Fick's law of diffusion, where cuticle and wax in particular represent the major rate-limiting barriers; 2) the permeances of pedicel surfaces exceed those of fruit surfaces; and 3) pedicel transpiration can be minimized by minimizing the driving force (difference in water vapor concentration) during postharvest handling and storage.
\end{abstract}

The pedicel of a sweet cherry fruit is a useful indicator of its postharvest freshness (Drake and Elfving, 2002; Sekse, 1996; Wani et al., 2014). Shriveled and brown pedicels are indicative of inadequate storage conditions, or a too long storage period, and so result in reduced value at point of sale and a commercial loss somewhere along the supply chain. Shriveling and browning result from postharvest water loss, loss of membrane integrity, and subsequent oxidation of phenols by polyphenol oxidases (PPO) and peroxidases and chlorophyll degradation (Lang and Thorpe, 1989; Linke et al., 2010; Sekse, 1996; Smith and Whiting, 2011; for review on browning resulting from PPO, see Vamos-Vigyazo, 1981). However, little is known about the mechanisms and pathways of water loss by a cherry fruit's pedicel (Linke et al., 2010; Smith and Whiting, 2011). The role played by the fruit in pedicel transpiration is not clear. Water loss from plant surfaces (including of fruit and pedicels) is usually described by Fick's law:

$$
F=A \times p \times \Delta C
$$

where $F$ (grams per second) is the measured rate of transpiration,

Received for publication 21 Nov. 2014. Accepted for publication 29 Dec. 2014 This research was funded in part by grants from the Deutsche Forschungsgemeinschaft, the Marktgemeinschaft Altes Land, and the German Academic Exchange Service (scholarship for Thomas O. Athoo).

We thank Friederike Schroeder and Simon Sitzenstock for technical support; and Drs. Eckhard Grimm, Bishnu P. Khanal, and Sandy Lang for helpful discussion and useful comments on an earlier version of the manuscript.

${ }^{1}$ Corresponding author. E-mail: moritz.knoche@obst.uni-hannover.de.
$A$ (square meters) the organ's surface area, and $\Delta C$ (grams per cubic meter) the difference in water vapor concentration between the inside and outside of the organ. The value $p$ (meters per second) is the permeance, which is a measure of the ease with which water can pass through the organ's skin. To date, estimates of $p$ are available only for the sweet cherry fruit surface (Knoche et al., 2000) with published information on the $p$ value of the pedicel surface being unavailable. Estimates of $p$ are suitable for characterizing and comparing water transfer across surfaces of fruit and pedicel, because $p$ is largely independent of $A$ and $\Delta C$ (Knoche et al., 2000).

The objectives of this study were to 1) quantify the permeances of transpiring fruit and of pedicel surfaces; 2) determine the role of the fruit in as much as it may affect pedicel transpiration; and 3) identify the effect of selected factors including temperature and $\mathrm{RH}$ on pedicel transpiration.

\section{Materials and Methods}

Plant material. Sweet cherry fruit of the cultivars Sam, Regina, Adriana, Dönissens Gelbe, Frühe Rote Mecklenburger, Hedelfinger, Kordia, Burlat, Merchant, Staccato, and Sweetheart were picked randomly from a minimum of three trees grafted on 'Gisela 5' rootstocks (Prunus cerasus L. $\times$ $P$. canescens Bois) grown under a rain shelter in the field or 
in an experimental greenhouse at the horticultural experiment station at Ruthe (lat. $52^{\circ} 14^{\prime} \mathrm{N}$, long. $9^{\circ} 49^{\prime} \mathrm{E}$ ) in the 2012,2013 , and 2014 seasons. Fruit were harvested early in the mornings and selected for absence of visible defects and for uniformity of maturity based on skin color and processed within $2 \mathrm{~h}$.

GeNerAL EXPERIMENTAL PROCEDURE. Fruit with and without their pedicels and/or detached excised pedicels were incubated at $22{ }^{\circ} \mathrm{C}$ in sealed polyethylene (PE) boxes at a defined water vapor concentration. Unless specified otherwise, pedicel length of fruit with pedicels was maintained constant within any one experiment by cutting the proximal portion using a razor blade. Fruit without pedicels were prepared by cutting their pedicels proximal of the receptacle and sealing the stem/fruit juncture and the receptacle including the pedicel end using an epoxy glue (UHU plus schnellfest; UHU, Bühl/Baden, Germany). Water loss was recorded by repeated weighings of individual fruit and/or pedicels. Rates of transpiration $(F)$ were calculated for each fruit or (detached) pedicel as the slope of a linear regression through a plot of cumulative mass loss against time. Pedicel transpiration was quantified by difference. This involved subtracting the average rate of transpiration of fruit without their pedicels from that of fruit with their pedicels. A preliminary experiment established that this method was straightforward and also yielded essentially the same values for pedicel transpiration rate as from less straightforward, but more direct, gravimetric determinations (see immediately below) of the amounts of water transpired by attached pedicels $\left[3.6 \pm 0.2\right.$ vs. $4.2 \pm 0.3 \mathrm{mg} \cdot \mathrm{h}^{-1}(\mathrm{n}=10$, $P<0.139)]$. The more direct determination of transpiration from fruit and also from their attached pedicels was accomplished in this preliminary experiment by inserting a still-attached pedicel through an orifice ( $3 \mathrm{~mm}$ diameter) in the lid of a falcon tube (29 $\mathrm{mm}$ diameter, $115 \mathrm{~mm}$ long) filled with dry silica gel and the whole assembly sealed in a PE box that also contained dry silica gel. In this way, the silica in the falcon tube served as a receiver for water transpired from the pedicel surface and that in the PE box as a receiver for water transpired from the fruit surface. Also, in contrast to salts, the silica in the falcon tube allowed the pedicel to be removed, fruit with pedicel weighed, and the pedicel to be re-inserted without any contamination of the pedicel surface. At selected intervals, fruit were removed from the PE box and from the falcon tube and both, fruit and the falcon tube (without the fruit), weighed. Rates of transpiration were calculated as described previously. From the rates of transpiration of fruit $\left(F_{\text {fruit }}\right)$ and pedicels $\left(F_{\text {pedicel }}\right)$, the permeances of the fruit $\left(p_{\text {fruit }}\right)$ and pedicel surfaces $\left(p_{\text {pedicel }}\right)$ were calculated. The value $A_{\text {fruit }}$ was calculated from fruit mass assuming a mean density of $1 \mathrm{~kg} \cdot \mathrm{dm}^{-3}$ and a spherical shape. Meanwhile, the value $A_{\text {pedicel }}$ was calculated from pedicel length and mean diameter [measured at the midpoint using digital calipers (CD-30PK; Mitutoyo, Kawasaki/Kanagawa, Japan)] and assuming a cylindrical shape. The $\Delta C$ (grams per cubic meter) represents the difference in water vapor concentration between the atmosphere within the fruit, or the pedicel, and that inside the PE box. The water vapor concentration inside the fruit and inside the pedicel is essentially saturated $\left[23.07 \mathrm{~g} \cdot \mathrm{m}^{-3}\right.$ at $22{ }^{\circ} \mathrm{C}$ (Nobel, 1999)]. With few exceptions where fruit and/or pedicels were incubated above silica or water, the PE box contained saturated salt slurries to establish defined humidities (Wexler, 1995). For example, saturated $\mathrm{NaCl}$, used in most experiments, generates a water vapor concentration of
$14.6 \mathrm{~g} \cdot \mathrm{m}^{-3}$ at $22{ }^{\circ} \mathrm{C}$. The water vapor concentration gradient driving transpiration of fruit and/or pedicel inside the PE box amounts to $8.47 \mathrm{~g} \cdot \mathrm{m}^{-3}$.

Experiments. The time course of water loss from fruit and pedicels was established over a 96-h period using mature 'Staccato' sweet cherry incubated above $\mathrm{NaCl}$. Pedicels were carefully detached at the spur and remained at their full length. The number of single fruit replicates was 12 .

To identify the source of the water transpired by the pedicel, transpiration was monitored for excised pedicels and pedicels that remained attached to their fruit (all above $\mathrm{NaCl}$ ). Pedicel length was standardized to $40 \mathrm{~mm}$ by cutting using a razor blade. The cultivar was Frühe Rote Mecklenburger. The number of individual fruit replicates was 10 .

The vascular system (xylem or phloem) that supplies the pedicel with water was identified by studying the effect of steam girdling and the effect of pedicel orientation in two separate experiments. In the first, the effect of steam girdling was quantified by monitoring transpiration of girdled and nongirdled pedicels (30 mm length) of 'Merchant' sweet cherry above $\mathrm{NaCl}$. The pedicels were girdled above the receptacle using a modified steam generator [width of girdle $5 \mathrm{~mm}$ (SC952; Alfred Kärcher, Winnenden, Germany)]. There was no contact between the steam and the fruit surface. Transpiration was quantified by repeated weighing of fruit with and without the pedicel as described previously. Fruit with nongirdled pedicels served as controls. The number of single fruit replicates was 10 . In the second experiment the effect of pedicel orientation was studied using excised pedicels of 'Frühe Rote Mecklenburger'. Pedicels were inserted through an orifice (2.2 $\mathrm{mm}$ diameter) in the lid of a 2-mL Eppendorf tube (CK 06.1; Carl Roth, Karlsruhe, Germany) such that either the basal or the apical end was immersed in water. The transpiring portion of the pedicel extended $25 \mathrm{~mm}$ beyond the seal. We refer to these orientations as the normal (basal end immersed in water in the Eppendorf tube) or reverse orientation (apical end immersed). To avoid cavitation, the pedicels were recut under water before being immersed in the Eppendorf tube. The tubes with pedicels inserted were incubated above $\mathrm{NaCl}$. The number of replicates was 10 where one replicate represented one pedicel.

The rate-limiting step in pedicel transpiration was investigated by modifying the pedicel surface using the following treatments. The cuticle was abraded from the surface of 'Regina' sweet cherry pedicels (40 $\mathrm{mm}$ length by razor blade) using abrasive paper (grit 600; Emil Lux, Wermelskirchen, Germany). Waxes were extracted by dipping excised pedicels once or five times for $10 \mathrm{~s}$ each in $\mathrm{CHCl}_{3} / \mathrm{MeOH}(1: 1 \mathrm{v} / \mathrm{v})$. Pedicel ends were sealed with fast-curing epoxy glue. Transpiration was quantified above $\mathrm{NaCl}$ by repeated weighing of the pedicels over a $1-\mathrm{h}$ period. The number of single pedicel replicates was 10 .

Differences in pedicel transpiration among cultivars were studied in Adriana, Burlat, Dönissens Gelbe, Frühe Rote Mecklenburger, Hedelfinger, Kordia, Regina, Sam, and Sweetheart. Pedicels were carefully detached at the spur and remained at their full length. Transpiration of fruit and pedicel incubated above $\mathrm{NaCl}$ was determined using 10 replicates. To relate pedicel transpiration to morphological characteristics, pedicel length, diameter, and stomatal densities were determined. Briefly, pedicel sections were photographed under a dissecting microscope (MZ6; Leica Mikrosysteme, Bensheim, 

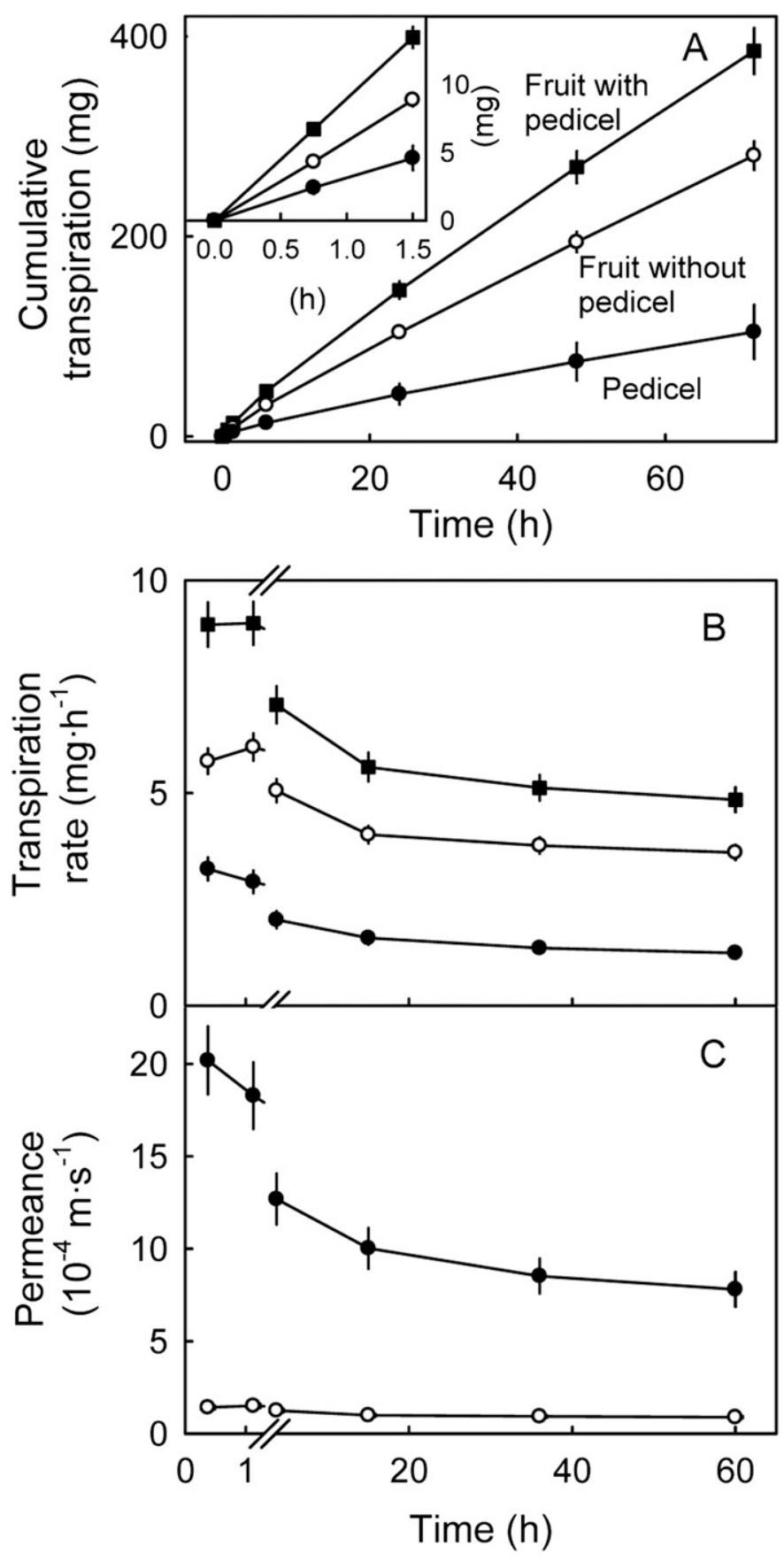

Fig. 1. Time course of transpiration of 'Staccato' sweet cherry fruit with and without pedicels and of pedicels: Transpiration of the pedicel was calculated by subtracting that of fruit without a pedicel from that of fruit with a pedicel. (A) Cumulative transpiration (inset: data from main graph redrawn on different time scale). (B) Rate of transpiration. (C) Permeance of the surfaces of both fruit and pedicel. Data represent means \pm SE.

Germany) and length and width quantified by image analysis (Cell ${ }^{\mathrm{P}}$; Olympus Europa, Hamburg, Germany). To establish the distribution of stomata along the pedicel, 'Sam' pedicels were cut into five sections each $\approx 8 \mathrm{~mm}$ in length, which were then cut along their long axes into two halves and incubated in $50 \mathrm{~mm}$ citric acid buffer solution ( $\mathrm{pH} 4.0$ ) containing $90 \mathrm{~mL} \cdot \mathrm{L}^{-1}$ pectinase (Panzym Super E flüssig; Novozymes, Bagsvaerd, Denmark), $5 \mathrm{~mL} \cdot \mathrm{L}^{-1}$ cellulase (Cellubrix L; Novozymes), and $\mathrm{NaN}_{3}$ at 30 mm (Orgell, 1955; Yamada et al., 1964). After $\approx 14 \mathrm{~d}$,

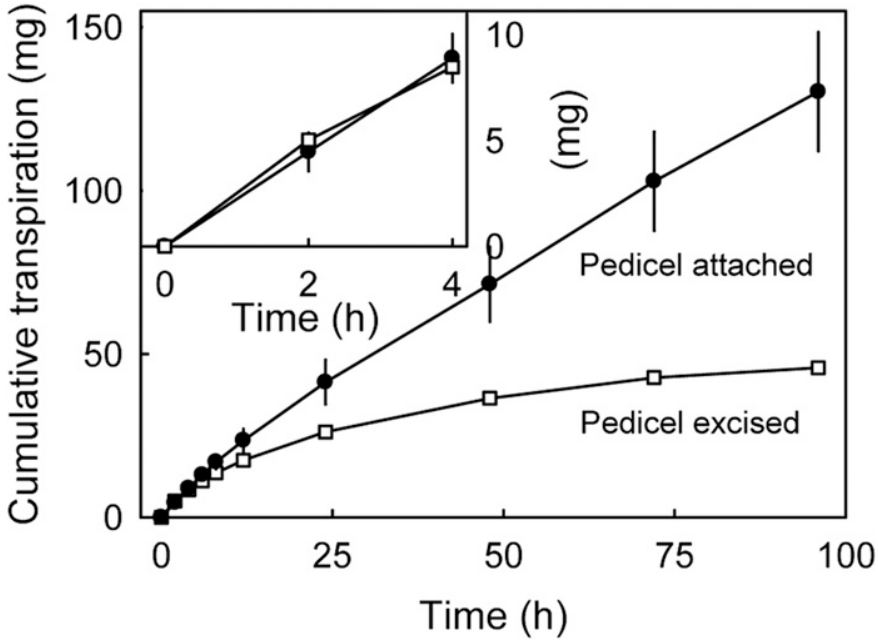

Fig. 2. Time course of transpiration of pedicels of 'Frühe Rote Mecklenburger' sweet cherries. Pedicels either remained attached to the fruit ("pedicel attached") or were excised such that the receptacle remained attached to the pedicel ("pedicel excised"). Transpiration of the attached pedicel was calculated by subtracting transpiration of fruit without pedicels from fruit with pedicels. (Inset) Same data as in the main graph but redrawn to a different scale. Data represent means $\pm \mathrm{SE}$.

the CMs had separated from adhering cell layers. The CMs were then spread on microscope slides, transferred to the stage of a fluorescence microscope (BX-60; Olympus Europa), and observed at $\times 100$. The number of stomata was determined in a representative area (range, 5 to $17 \mathrm{~mm}^{2}$ ) of both halves of each segment. Stomatal density was calculated by dividing the number of stomata by the area counted. Preliminary experiments established that there was no significant strain relaxation of the $\mathrm{CM}$ strips after isolation. For the cultivar comparison, stomatal densities were determined for the midportion of the pedicel. Total stomata number per pedicel was calculated by multiplying the density of stomata in the midportion by the surface area of the whole pedicel. Pedicel dimensions and stomatal densities were determined using five replicates.

The role of stomata in pedicel transpiration was addressed using two different approaches. In the first approach, 'Staccato' fruit with and without pedicel (length $40 \mathrm{~mm}$ ) were incubated in PE boxes closed with transparent Saran wrapping (Frischhaltefolie; REWE Handelsgruppe, Cologne, Germany). The PE boxes were continuously flushed with $\mathrm{CO}_{2}, \mathrm{~N}_{2}$, or ambient air after passing through dry silica. These atmospheres are expected to reduce, increase, or not affect (respectively) the extent of stomatal opening (F. Lenz, personal communication). Pedicel transpiration was quantified over a 5 -h interval $(n=5)$. For the second approach, 'Frühe Rote Mecklenburger' pedicels $(40 \mathrm{~mm})$ with fruit still attached were incubated for $1 \mathrm{~h}$ into $0.1 \mathrm{~mm}$ abscisic acid (ABA) prepared in $10 \mathrm{~mm}$ citric acid buffer at $\mathrm{pH}$ 3.6. Buffer solution without ABA served as a control. Transpiration of fruit with and without pedicels was monitored gravimetrically over a 6 - $h$ period as described previously. The number of single fruit replicates was 10 .

The effect of temperature on 'Sam' fruit and pedicel transpiration was investigated after a $24-\mathrm{h}$ incubation period at $2,12,22$, and $35^{\circ} \mathrm{C}$ above dry silica gel. The number of individual fruit replicates was 15 .

To test the effect of RH, 'Sam' fruit with and without pedicels ( $30 \mathrm{~mm}$ length) were incubated above dry silica gel 
Table 1. Permeance and resistance (r) to water movement through the pedicel surface of sweet cherry fruit. ${ }^{z}$

\begin{tabular}{|c|c|c|c|c|}
\hline & \multirow[b]{2}{*}{ Resistors } & \multirow{2}{*}{$\frac{\text { Permeance }}{\left[\text { mean } \pm \mathrm{SE}\left(10^{-4} \mathrm{~m} \cdot \mathrm{s}^{-1}\right)\right]}$} & \multicolumn{2}{|c|}{ Resistance } \\
\hline Treatments & & & {$\left[\right.$ mean $\left.\pm \mathrm{SE}\left(\mathrm{s} \cdot \mathrm{m}^{-1}\right)\right]$} & $(\%$ of total $)$ \\
\hline Control & CM, cell wall & $4.3 \pm 0.4^{\mathrm{y}}$ & $2,328^{x}$ & 100 \\
\hline Abrasive paper & Cell wall & $50.8 \pm 1.2^{\mathrm{y}}$ & $197^{x}$ & 8 \\
\hline $5 \times \mathrm{CHCl}_{3} / \mathrm{MeOH}$ & DCM + cell wall & $21.8 \pm 1.4^{y}$ & $459^{x}$ & 20 \\
\hline & $\mathrm{CM}$ & $4.7^{\mathrm{v}}$ & $2,131^{\mathrm{w}}$ & 92 \\
\hline & WAX & $5.4^{\mathrm{v}}$ & $1,869^{\mathrm{w}}$ & 80 \\
\hline
\end{tabular}

${ }^{\mathrm{z}}$ The cuticular membrane (CM) was abraded from the pedicel surface using abrasive paper, wax was removed from pedicels by a single $10 \mathrm{~s}$ dip in 1:1 v: $\mathrm{CHCl}_{3} / \mathrm{MeOH}$ [mostly epicuticular wax (ECW)], or by five 10 -s dips in $\mathrm{CHCl}_{3} / \mathrm{MeOH}$ [essentially all wax (WAX)]. The dewaxed CM after five dippings is referred to as DCM. Calculations are based on the analogy with Ohm's law for series resistances.

${ }^{\mathrm{y}}$ Experimentally determined permeance results.

${ }^{\mathrm{x}}$ Calculated as the inverse of the respective permeance.

${ }^{\text {w }}$ Calculated by difference from $r_{\mathrm{CM}+\text { cell wall }}=r_{\mathrm{CM}}+\mathrm{r}_{\text {cell wall }}$ and $\mathrm{r}_{\mathrm{DCM}}=\mathrm{r}_{\mathrm{CM}}-\mathrm{r}_{\mathrm{WAX}}$.

${ }^{\mathrm{v}}$ Calculated as the inverse of the respective resistance.

[0\% RH (Geyer and Schönherr, 1988)], saturated slurries of $\mathrm{CaCl}_{2}(28 \% \mathrm{RH}), \mathrm{NaCl}(75 \% \mathrm{RH}), \mathrm{KNO}_{3}[92 \% \mathrm{RH}$ (Wexler, $1995)$ ], or above water $(100 \% \mathrm{RH})$. The number of individual fruit replicates was 10 .

Data ANALYsis. Data in tables and figures are presented as means \pm SE. The following equation was used to calculate SES of pedicel transpiration $(\mathrm{z})$ obtained by the difference from the mean transpiration of fruit with pedicels $\left(\mathrm{x}_{1}\right)$ minus that without pedicels $\left(\mathrm{x}_{2}\right)$ (Sachs, 1992):

$$
S E_{z}=\sqrt{S E_{x 1}^{2}+S E_{x 2}^{2}}
$$

Where error bars are not visible, they are smaller than the data symbols.

\section{Results}

Cumulative transpiration of fruit with and without pedicels and of the detached pedicels increased with time (Fig. 1A). Rates of transpiration remained essentially constant during the first $6 \mathrm{~h}$ of an experiment but later declined, approaching an asymptote within $24 \mathrm{~h}$ (Fig. 1B). Calculating the values of $p$ for pedicel and fruit surfaces revealed that $p$ for pedicel surfaces exceeded that for fruit surfaces severalfold. Values were also constant, essentially independent of time under steady-state conditions over the first $6 \mathrm{~h}$ of the experiment (Fig. 1C). Thereafter, the apparent values of $p$ for the pedicel decreased steadily, probably as the water vapor concentration within the pedicel decreased with drying.

There was no significant difference in the initial rates of transpiration of attached and excised pedicels up to $\approx 4 \mathrm{~h}[2.22 \pm$ 0.29 vs. $2.12 \pm 0.11 \mathrm{mg} \cdot \mathrm{h}^{-1}$ for attached vs. excised pedicels, respectively $(P=0.75)$ (Fig. 2 inset)]. However, as time proceeded, rates of transpiration of excised pedicels decreased more rapidly than those of pedicels that remained attached to the fruit (Fig. 2). At $96 \mathrm{~h}$, dry matter concentration of detached pedicels had increased from $27.5 \% \pm 0.7 \%$ to $78.2 \% \pm 1.0 \%$, whereas that from pedicels that remained attached to their fruit increased only from $27.5 \% \pm 0.7 \%$ to $42.4 \% \pm 0.5 \%$. The total amount of water transpired by attached pedicels exceeded the amount of water in the pedicels indicating the water transpired by them came at least partly from the fruit.

Steam girdling pedicels (attached to the fruit) had no significant effect on pedicel transpiration $[1.58 \pm 0.15$ vs. $1.79 \pm 0.13 \mathrm{mg} \cdot \mathrm{h}^{-1}(P=0.29)$ for girdled vs. non-girdled pedicels]. Also, there was no effect of orientation of excised pedicels that were placed in Eppendorf tubes (like cut flowers in a vase) $\left[1.86 \pm 0.09 \mathrm{vs} .1 .92 \pm 0.14 \mathrm{mg} \cdot \mathrm{h}^{-1}(P=0.71)\right.$ for normal vs. reverse orientation].

Abrading the cuticle from the pedicel surface or dipping pedicels into $\mathrm{CHCl}_{3} / \mathrm{MeOH}$ increased rates of transpiration and also increased $p$ (Table 1). Dipping five times in $\mathrm{CHCl}_{3} / \mathrm{MeOH}$ was more effective than a single dip (Table 1). Assuming that 1) treatment with abrasive paper effectively removes the whole cuticle from the pedicel surface; and 2) five dips in $\mathrm{CHCl}_{3}$ / $\mathrm{MeOH}$ removes all wax (epicuticular plus intracuticular) allows estimation of the relative contributions to total resistance of the pedicel surface by the cell wall, the wax, and the cutin. These calculations reveal that the cuticle and, particularly, the wax are responsible for most of the resistance to water movement (Table 1).

Pedicels of sweet cherries differed in length and diameter (data not shown), surface area, and stomatal density (Table 2). Stomatal density varied along the pedicel, increasing gradually from the proximal end toward the distal (fruit) end but then decreasing somewhat close to the receptacle (Fig. 3A). Across cultivars, pedicel stomatal density averaged $\approx 38.5$ stomata/ $\mathrm{mm}^{2}$ [range, 29.6 to 56.2 stomata/ $/ \mathrm{mm}^{2}$ (Table 2)]. There was no significant correlation between stomatal density on the fruit and pedicel surfaces $(r=0.24, P=0.65)$ or between the total number of stomata on fruit and pedicel $(r=0.20, P=0.71)$. Also, rates of transpiration were not significantly related to pedicel surface area $\left[r^{2}=0.04, P=0.61\right.$ (Fig. 3B) $]$ or to total numbers of stomata per pedicel $\left[r^{2}=0.13, P=0.34\right.$ (Fig. 3C)]. There was no significant relationship between the permeance and stomatal density of pedicel surfaces $\left[r^{2}=0.10, P=0.41\right.$ (Fig. 3D)].

Incubation in $\mathrm{CO}_{2}$ - or $\mathrm{N}_{2}$-atmospheres had no effect on pedicel transpiration when compared with that of fruit held in ambient air (Table 3). Also, ABA treatment had no effect on rates of pedicel transpiration.

Transpiration rates of fruit with and without pedicels and those of pedicels (calculated) increased exponentially as 
Table 2. Pedicel surface area, stomatal density, total number of stomata per pedicel, and rates of transpiration and permeances of pedicels and fruit of selected sweet cherry cultivars. ${ }^{\mathrm{z}}$

\begin{tabular}{|c|c|c|c|c|c|c|c|}
\hline \multirow[b]{3}{*}{ Cultivar } & \multirow{2}{*}{$\begin{array}{c}\text { Surface area } \\
\text { pedicel } \\
\left(\mathrm{mm}^{2}\right) \\
\end{array}$} & \multirow{2}{*}{$\begin{array}{c}\text { Stomatal density } \\
\text { on pedicel } \\
\left(\text { stomata } / \mathrm{mm}^{2}\right)\end{array}$} & \multirow{2}{*}{$\begin{array}{c}\text { Total stomata } \\
\text { (no.) }\end{array}$} & \multicolumn{2}{|c|}{$\begin{array}{c}\text { Rate of transpiration } \\
\left(\mathrm{mg} \cdot \mathrm{h}^{-1}\right)\end{array}$} & \multicolumn{2}{|c|}{$\begin{array}{l}\text { Permeance } \\
\left(10^{-4} \mathrm{~m} \cdot \mathrm{s}^{-1}\right)\end{array}$} \\
\hline & & & & Pedicel & Fruit & Pedicel & Fruit \\
\hline & \multicolumn{7}{|c|}{$($ mean $\pm \mathrm{SE})$} \\
\hline Burlat & $131 \pm 3$ & $31.1 \pm 1.3$ & $4,101 \pm 235$ & $3.3 \pm 0.7$ & $14.6 \pm 0.7$ & $12.3 \pm 2.3$ & $3.7 \pm 0.2$ \\
\hline Dönissens Gelbe & $220 \pm 2$ & $41.3 \pm 1.1$ & $9,091 \pm 113$ & $2.1 \pm 0.2$ & $7.2 \pm 0.3$ & $4.8 \pm 0.4$ & $2.4 \pm 0.1$ \\
\hline $\begin{array}{l}\text { Frühe Rote } \\
\text { Mecklenburger }\end{array}$ & $238 \pm 4$ & $29.6 \pm 1.5$ & $6,724 \pm 174$ & $4.1 \pm 0.6$ & $8.8 \pm 0.3$ & $9.4 \pm 1.3$ & $2.4 \pm 0.1$ \\
\hline Hedelfinger & $185 \pm 4$ & $47.3 \pm 1.4$ & $9,252 \pm 207$ & $3.0 \pm 0.4$ & $9.0 \pm 0.4$ & $9.2 \pm 0.9$ & $2.3 \pm 0.1$ \\
\hline Kordia & $202 \pm 4$ & $30.6 \pm 0.8$ & $5,938 \pm 156$ & $2.9 \pm 0.2$ & $8.6 \pm 0.6$ & $7.0 \pm 0.9$ & $1.9 \pm 0.1$ \\
\hline Regina & $256 \pm 7$ & $38.1 \pm 1.0$ & $10,117 \pm 457$ & $4.5 \pm 0.1$ & $7.5 \pm 0.3$ & $9.5 \pm 0.5$ & $1.8 \pm 0.1$ \\
\hline Sam & $188 \pm 1$ & $56.2 \pm 1.4$ & $11,027 \pm 180$ & $2.8 \pm 0.1$ & $6.3 \pm 0.2$ & $7.6 \pm 0.3$ & $1.6 \pm 0.0$ \\
\hline Sweetheart & $147 \pm 2$ & $36.6 \pm 1.5$ & $5,423 \pm 155$ & $2.0 \pm 0.2$ & $5.5 \pm 0.3$ & $7.6 \pm 0.8$ & $1.4 \pm 0.1$ \\
\hline Grand mean & $190 \pm 3$ & $38.5 \pm 1.3$ & $7,397 \pm 363$ & $3.0 \pm 0.1$ & $8.1 \pm 0.3$ & $8.7 \pm 0.4$ & $2.1 \pm 0.1$ \\
\hline
\end{tabular}

${ }^{\mathrm{z}}$ Rates of transpiration were quantified gravimetrically after incubation above saturated $\mathrm{NaCl}$.

temperature increased (Fig. 4A). This increase resulted from an increase in the driving force, whereas temperature had no effect on the permeance of the surfaces of either fruit or pedicel. Again, the permeances of the pedicel surfaces greatly exceeded those of the fruit surfaces (Fig. 4B).

Transpiration rates were inversely related to $\mathrm{RH}$ for fruit with and without pedicels and for the pedicels, but permeances of pedicel and fruit surfaces were largely independent of RH. Furthermore, the permeance of the pedicel surface consistently exceeded that of the fruit surface (Fig. 5).

\section{Discussion}

Our data establish that: 1) a fruit serves as a water supply to support pedicel transpiration; 2) pedicel transpiration may be described by Fick's law; 3 ) the $p$ of the pedicel surface exceeds that of the fruit surface by, on average 5-fold; and 4) increasing temperature and decreasing $\mathrm{RH}$ increases the driving force for transpiration but had no effect on the value of $p$ for the pedicel surface.

The FRUit SUSTAINS PEdicel tRanspiration THROUgh THE XYLEM. A fruit serves as a water supply to sustain the transpiration of an attached pedicel. This conclusion is supported by several arguments. First, pedicels that remained attached to the fruit had an approximate constant rate of water loss up to $\approx 4 \mathrm{~h}$, when rates began to decrease somewhat (Figs. $1 \mathrm{~B}$ and 2). Indeed, the cumulative transpiration of pedicels soon exceeded their own total water contents, indicating that the water they transpired must have been obtained from the fruit (Fig. 2). Second, initial rates of transpiration were similar for excised and for attached pedicels (Fig. 2 inset). From this observation we infer that initial rates of transpiration are governed by properties of the pedicel surface rather than by any restriction of water supply imposed by the vascular connection to the fruit. The decline in the transpiration rates of excised pedicels after some hours is explained by their limited fresh weight and, consequently, the small amount of available water they contain.

Water transfer from fruit to a transpiring pedicel occurs mainly through the xylem. This conclusion is based on the lack of any effect of steam girdling on pedicel transpiration and also on the lack of an effect of pedicel orientation. Steam girdling interrupts phloem transport by killing its cells. In contrast, xylem conductance is unaffected by steam girdling and is independent of the direction of water flow (Lang and Thorpe, 1989). It may be argued that the formation of an abscission layer at the fruit/pedicel juncture could affect postharvest pedicel transpiration by affecting the conductance of the vascular system. However, studies with a number of cultivars have shown that formation of an abscission layer (as indexed by a declining pedicel-fruit retention force) is not related to any change in vascular connectivity between a fruit and its pedicel (Smith and Whiting, 2011). Also, in earlier anatomical studies there is no evidence that an abscission layer might interrupt the vascular bundles of mature 'Windsor' sweet cherries (Wittenbach and Bukovac, 1972). This would be a prerequisite for any effect of an abscission layer on pedicel transpiration. Based on these arguments, we do not expect abscission layer formation to be a significant factor in regulating pedicel transpiration.

Pedicel transpiration obeyed fick's law. Water movement through the cuticular membrane of the pedicel surface was the rate-limiting step in transpiration. The effects of various factors on transpiration rate were accounted for by their effects either on permeance and/or on the driving force.

On average, the permeance of the pedicel surface exceeded that of the fruit 4-fold. It may be argued that because the pedicel surface is stomatous, this $p$ is a composite (in parallel) property comprising both stomatal and cuticular conductance components. Furthermore, the stomatal $p$ component is expected to be a function of stomatal density and/or stomatal pore area. Stomatal densities on pedicel surfaces were on average 40-fold higher than on fruit surfaces (Table 2; Peschel et al., 2003; Peschel and Knoche, 2012). However, there is evidence here that stomata did not play a major role in determining pedicel transpiration. First, there was no significant relationship between total stomatal number and the rate of transpiration or between stomatal density and the $p$ of the pedicel surface (Fig. 3C and D). Second, none of the treatments known to induce stomatal closure or opening (such as dipping in $\mathrm{ABA}$ or incubation in $\mathrm{CO}_{2}$ - or $\mathrm{N}_{2}$-atmospheres) had any effect on transpiration (Table 3). If stomata were functional, we would expect $\mathrm{ABA}$ or $\mathrm{CO}_{2}$ atmosphere to decrease and $\mathrm{N}_{2}$ to increase 

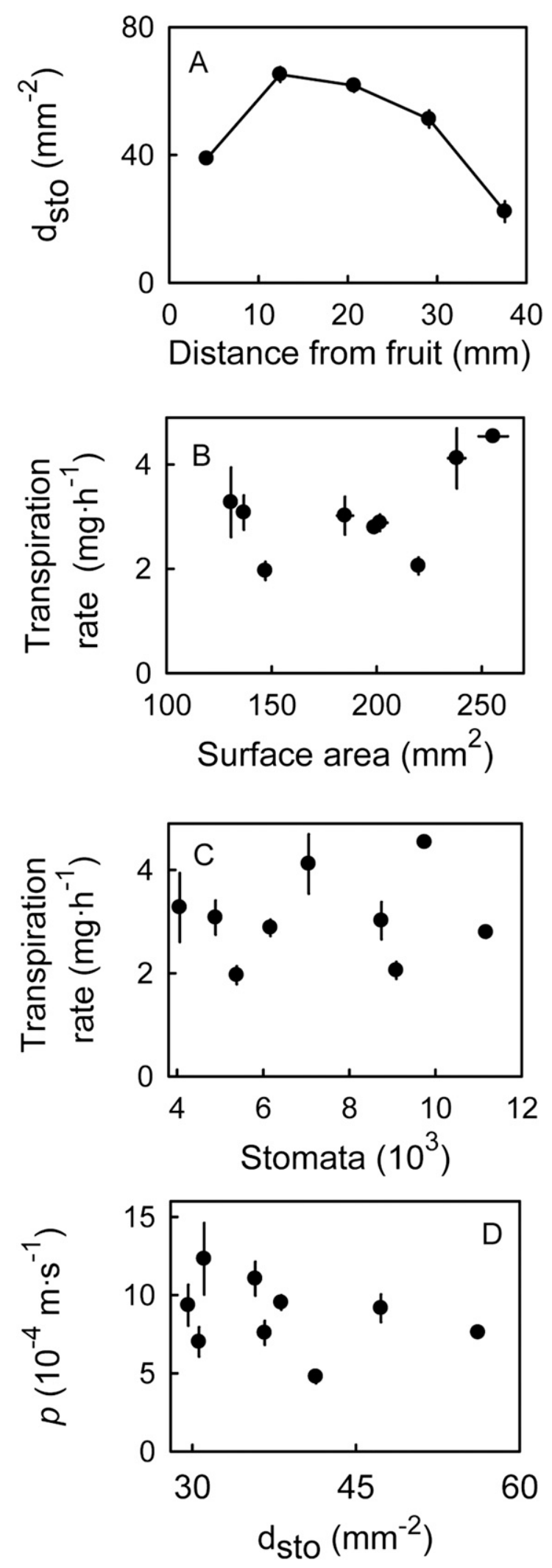

Fig. 3. (A) Stomatal densities $\left(\mathrm{d}_{\mathrm{sto}}\right)$ along the sweet cherry fruit pedicel from the receptacle at the fruit (position $0 \mathrm{~cm}$ ) to the spur end at the pedicel base (position $40 \mathrm{~mm}$ ). (B) Relationship between rate of transpiration of the pedicel of different cultivars and pedicel surface area. For cultivar names, see Table 3. (C) Relationship between rate of transpiration of the pedicel and total number of stomata on the pedicel. (D) Relationship between permeance $(p)$ of the pedicel surface and stomatal density. Data represent means $\pm \mathrm{SE}$. transpiration as compared with the non-treated control. Third, we were unable to detect any changes in stomatal aperture in the course of dehydration or in response to ABA treatments (T. Athoo, unpublished data). Fourth, the water potential of sweet cherry fruit is very negative as a result of the high concentration of carbohydrates and the absence of significant turgor (Knoche et al., 2014). This negative water potential would impose significant water stress on the fruit pedicel causing stomata to close (assuming they were functional). Stomata on the surface of mature fruit have been shown to be non-functional (Peschel et al., 2003). Finally, under bestpractice postharvest conditions, packaged fruit is held in the dark, often in a high $\mathrm{CO}_{2}$ atmosphere, and both factors are likely to close off any still-functional stomata.

The lack of a significant contribution of stomatal transpiration to total pedicel transpiration and the apparent absence of significant relationships between rates of transpiration and pedicel surface area in the between-cultivar comparison imply the permeability of the cuticle between stomata must differ significantly between cultivars. Such differences could be the result of differing amounts of wax or differences in the composition and crystallinity of the wax. It is clear that the wax and, within the wax, the fraction extracted by the first chloroform/methanol dip contribute the major resistances to transpiration. It may be speculated that the first dip primarily removed epicuticular wax, which is located on the cuticle surface and, hence, more readily accessible to the solvents. However, 1) solubility differs between wax constituents; and 2) solvents will also penetrate into the cuticle and both factors will limit spatial selectivity of the extraction procedure. Unfortunately, as a result of the fragility of the pedicel cuticle, conclusive direct evidence is difficult to obtain.

The effect of temperature and $\mathrm{RH}$ on transpiration is also accounted for by Fick's law. Both factors alter the driving force for transpiration but neither had a significant effect on the permeance of the pedicel surface. Interestingly, when fruit with pedicels were held for several days, slight shriveling of the pedicel was observed even in a water-saturated atmosphere. According to Linke et al. (2010), pedicel shriveling is a linear function of the pedicel's water content. However, the shriveling in the long-term incubation cannot be accounted for by transpiration, because fruit actually gained mass slightly under these conditions (T. Athoo, unpublished data). Thus, additional factors must have been involved. The mechanistic basis of pedicel dehydration under a water-saturated atmosphere is currently under investigation.

\section{Conclusions}

Our work is consistent with previous work demonstrating the importance of minimizing the driving force for transpiration during storage (Hevia et al., 1998; Linke et al., 2010; Manganaris et al., 2007; Schick and Toivonen, 2002; Sekse and Lyngstad, 1996; Stow et al., 2004; Wani et al., 2014). The other two determinants of water vapor transfer in Fick's law are pedicel surface area and stomatal number. Both are effectively constant for a given cultivar. Furthermore, the stomata on the pedicel appear non-functional and, hence, probably cannot be manipulated in the postharvest chain.

From a practical point of view, transpiration can only be minimized by decreasing the driving force for transpiration 
Table 3. Effect of manipulating stomatal opening on pedicel transpiration in mature sweet cherry fruit. ${ }^{z}$

\begin{tabular}{llrr}
\hline & & \multicolumn{2}{c}{ Rate of transpiration $\left[\mathrm{mean} \pm \mathrm{SE}\left(\mathrm{mg} \cdot \mathrm{h}^{-1}\right)\right]$} \\
\cline { 2 - 4 } Treatment & \multicolumn{1}{c}{ Cultivar } & Fruit with pedicel & Fruit without pedicel \\
\hline Ambient atmosphere & Staccato & $33.7 \pm 1.7$ & $23.3 \pm 1.1$ \\
$\mathrm{CO}_{2}$ & Staccato & $29.1 \pm 1.5$ & $19.7 \pm 0.5$ \\
$\mathrm{~N}_{2}$ & Staccato & $32.6 \pm 1.4$ & $9.4 \pm 2.0$ \\
Control & Frühe Rote Mecklenburger & $13.3 \pm 0.7$ & $23.9 \pm 1.0$ \\
ABA & Frühe Rote Mecklenburger & $13.1 \pm 0.7$ & $9.3 \pm 0.6$ \\
\end{tabular}

"'Staccato' sweet cherry fruit with and without pedicels were incubated above dry silica in polyethylene boxes flushed with $\mathrm{N}_{2}, \mathrm{CO}_{2}$, or ambient air. Pedicels of 'Frühe Rote Mecklenburger' sweet cherry were incubated for $1 \mathrm{~h}$ in $0.1 \mathrm{~mm}$ abscisic acid (ABA) prepared in $10 \mathrm{~mm}$ citrate buffer ( $\mathrm{pH}$ 3.6) to induce stomatal closure. Pedicels incubated in buffer only served as controls. Pedicel transpiration was calculated by subtracting that of fruit with pedicles from that of fruit without pedicels.

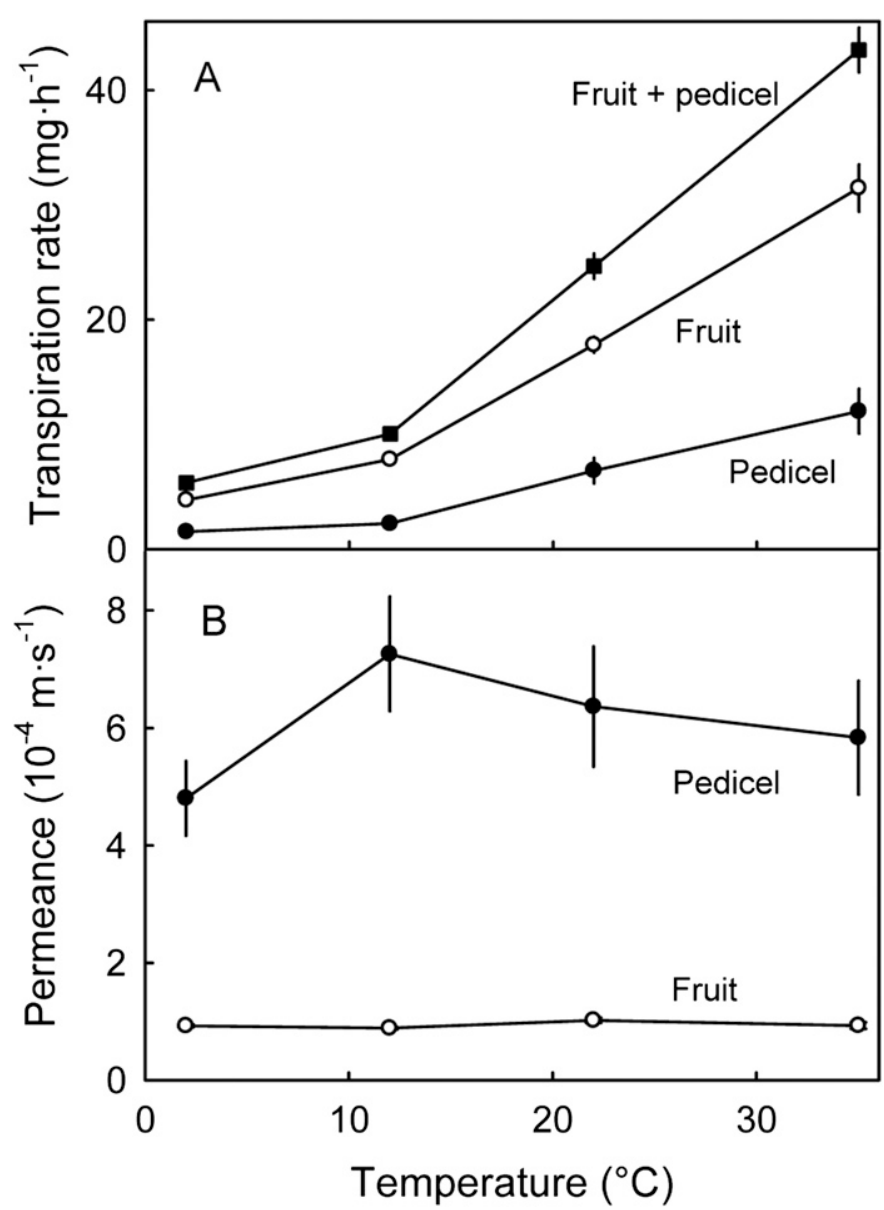

Fig. 4. Effect of temperature on rates of transpiration of sweet cherry fruit with and without pedicels and of the pedicel (A) and on permeances of surfaces of fruit and pedicel $(\mathbf{B})$. Pedicel transpiration was calculated by subtracting the transpiration rate of fruit without pedicels from that of fruit with pedicels. Fruit were incubated at the respective temperature above dry silica. Data represent means $\pm \mathrm{SE}$.

during storage. The most effective way to reduce transpiration is to quickly reduce the driving force for transpiration by rapid cooling. Indeed, hydrocooling has been shown to reduce stem browning and surface shriveling (Manganaris et al., 2007). In addition, modified atmosphere packaging is used to reduce water loss by increasing boundary layer resistance (still air) and by maintaining a high $\mathrm{RH}$ environment around the fruit (Alique et al., 2003; Kappel et al., 2002; Padilla-Zakour et al., 2004; Wani et al., 2014).

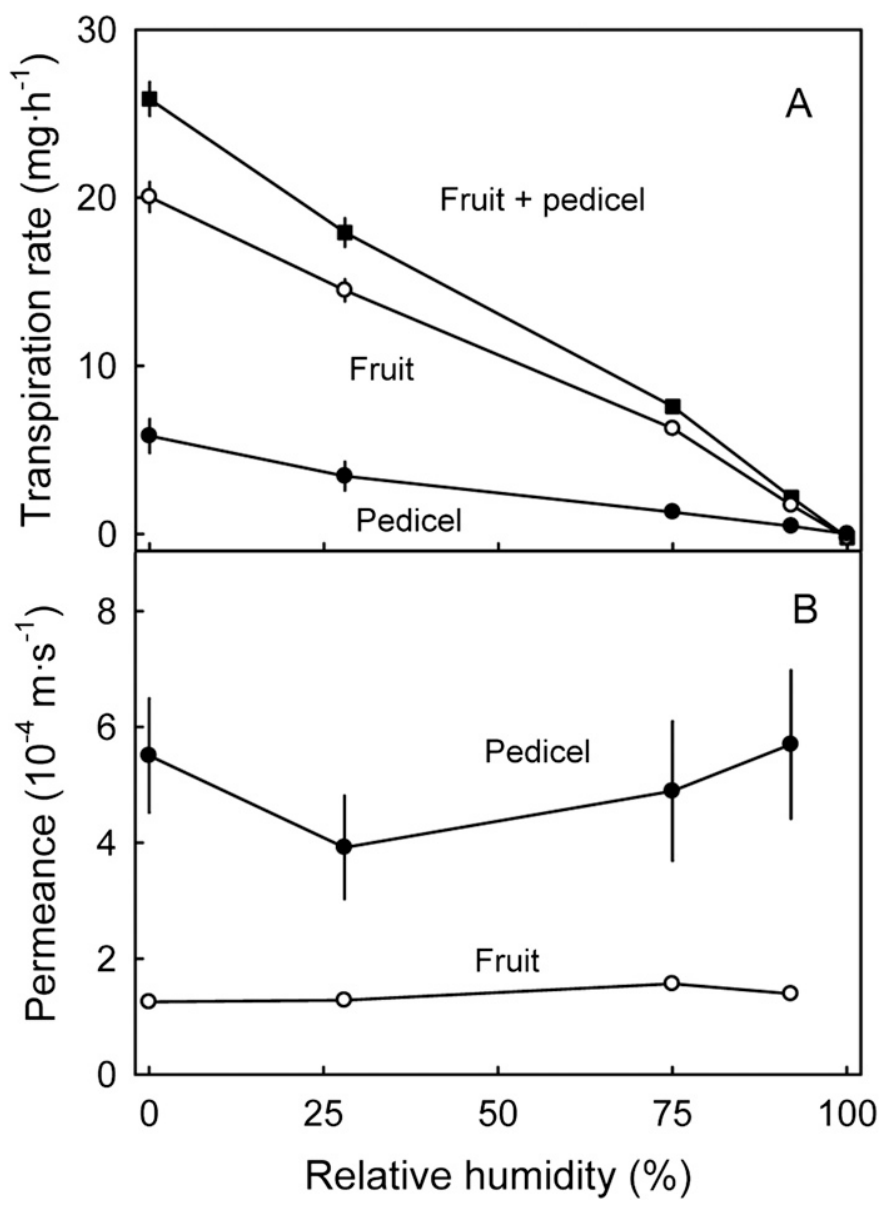

Fig. 5. Effect of relative humidity (RH) on the rates of transpiration of sweet cherry fruit with and without pedicels and of pedicels (A) and on the permeances of the surfaces of fruit and pedicels (B). Pedicel transpiration was calculated by subtracting the transpiration rates of fruit without pedicels from those of fruit with pedicels. Relative humidity was varied at constant temperature using dry silica $(0 \% \mathrm{RH})$, saturated slurries of $\mathrm{CaCl}_{2}(28 \% \mathrm{RH})$, $\mathrm{NaCl}(75 \% \mathrm{RH}), \mathrm{KNO}_{3}(92 \% \mathrm{RH})$, or water $(100 \% \mathrm{RH})$. Data represent means \pm SE.

\section{Literature Cited}

Alique, R., M.A. Martínez, and J. Alonso. 2003. Influence of the modified atmosphere packaging on shelf life and quality of Navalinda sweet cherry. Eur. Food Res. Technol. 217:416-420.

Drake, S.R. and D.C. Elfving. 2002. Indicators of maturity and storage quality of Lapins sweet cherry. Hort Technology 12:687-690.

Geyer, U. and J. Schönherr. 1988. In vitro test for effects of surfactants and formulations on permeability of plant cuticles, p. 21-33. In: 
Cross, B. and H.B. Scher (eds.). Pesticide formulations: Innovations and developments. Amer. Chem. Soc., Washington, DC.

Hevia, F., R. Wilckens, P. Lanuza, C. Mujica, and Y. Olave. 1998. Influence of hydrocooling and fruit color on the behavior of Bing sweet cherries after refrigerated storage. Acta Hort. 468:731736.

Kappel, F., P. Toivonen, D.-L. McKenzie, and S. Stan. 2002. Storage characteristics of new sweet cherry cultivars. HortScience 37:139143.

Knoche, M., E. Grimm, and H.J. Schlegel. 2014. Mature sweet cherries have low turgor. J. Amer. Soc. Hort. Sci. 139:3-12.

Knoche, M., S. Peschel, M. Hinz, and M.J. Bukovac. 2000. Studies on water transport through the sweet cherry fruit surface: Characterizing conductance of the cuticular membrane using pericarp segments. Planta 212:127-135.

Lang, A. and M.R. Thorpe. 1989. Xylem, phloem and transpiration flows in a grape: Application of a technique for measuring the volume of attached fruits to high resolution using Archimedes' principle. J. Expt. Bot. 40:1069-1078.

Linke, M., W.B. Herppich, and M. Geyer. 2010. Green peduncles may indicate postharvest freshness of sweet cherries. Postharvest Biol. Technol. 58:135-141.

Manganaris, G.A., I.F. Ilias, M. Vasilakakis, and I. Mignani. 2007. The effect of hydrocooling on ripening related quality attributes and cell wall physicochemical properties of sweet cherry fruit (Prunus avium L.). Intl. J. Refrig. 30:1386-1392.

Nobel, P.S. 1999. Physicochemical and environmental plant physiology. 2nd Ed. Academic Press, San Diego, CA.

Orgell, W.H. 1955. The isolation of plant cuticle with pectic enzymes. Plant Physiol. 30:78-80.

Padilla-Zakour, O.I., K.S. Tandon, and J.M. Wargo. 2004. Quality of modified atmosphere packaged 'Hedelfingen' and 'Lapins' sweet cherries. HortTechnology 14:331-337.
Peschel, S., M. Beyer, and M. Knoche. 2003. Surface characteristics of sweet cherry fruit: Stomata-Number, distribution, functionality and surface wetting. Sci. Hort. 97:265-278.

Peschel, S. and M. Knoche. 2012. Studies on water transport through the sweet cherry fruit surface: XII. Variation in cuticle properties among cultivars. J. Amer. Soc. Hort. Sci. 137:367-375.

Sachs, L. 1992. Angewandte Statistik. 7th Ed. Springer, Berlin, Germany. Schick, J.L. and P.M.A. Toivonen. 2002. Reflective tarps at harvest reduce stem browning and improve fruit quality of cherries during subsequent storage. Postharvest Biol. Technol. 25:117-121.

Sekse, L. 1996. Respiration and storage potential in Norwegian-grown sweet cherries. Acta Hort. 410:357-362.

Sekse, L. and L. Lyngstad. 1996. Strategies for maintaining high quality in sweet cherries during harvesting, handling and marketing. Acta Hort. 410:351-355.

Smith, E.D. and M.D. Whiting. 2011. The pedicel's role in postharvest weight loss of two sweet cherry cultivars. Acta Hort. 903:935-939.

Stow, J.R., J. Jameson, and K. Senner. 2004. Storage of cherries: The effects of rate of cooling, store atmosphere and store temperature on storage and shelf-life. J. Hort. Sci. Biotechnol. 79:941-946.

Vamos-Vigyazo, L. 1981. Polyphenol oxidase and peroxidase in fruits and vegetables. CRC Crit. Rev. Food Sci. Nutr. 15:49-127.

Wani, A.A., P. Singh, K. Gul, M.H. Wani, and H.C. Langowski. 2014. Sweet cherry (Prunus avium): Critical factors affecting the composition and shelf life. Food Packaging Shelf Life 1:86-99.

Wexler, A. 1995. Constant humidity solutions, p. 15-23. In: Lide, D.R. (ed.). Handbook of chemistry and physics. 76th Ed. CRC Press, Boca Raton, FL.

Wittenbach, V.A. and M.J. Bukovac. 1972. An anatomical and histochemical study of abscission in maturing sweet cherry fruit. J. Amer. Soc. Hort. Sci. 97:214-219.

Yamada, Y., S.H. Wittwer, and M.J. Bukovac. 1964. Penetration of ions through isolated cuticles. Plant Physiol. 39:28-32. 